\title{
Country-level structural stigma, identity concealment, and day-to-day discrimination as determinants of transgender people's life satisfaction
}

\author{
Richard Bränström ${ }^{1} \mathbb{D}$. John E. Pachankis ${ }^{2}$
}

Received: 15 September 2020 / Accepted: 29 January 2021 / Published online: 13 February 2021

(c) The Author(s) 2021

\begin{abstract}
Purpose Discriminatory laws, policies, and population attitudes, surrounding transgender people vary greatly across countries, from equal protection under the law and full acceptance to lack of legal recognition and open bias. The consequences of this substantial between-country variation on transgender people's health and well-being is poorly understood. We therefore examined the association between structural stigma and transgender people's life satisfaction across 28 countries.

Methods Data from transgender participants $(n=6771)$ in the 2012 EU-LGBT-survey regarding identity concealment, day-to-day discrimination, and life satisfaction were assessed. Structural stigma was measured using publicly available data regarding each country's discriminatory laws, policies, and population attitudes towards transgender people.

Results Multilevel models showed that country-level structural stigma was associated with lower life satisfaction, an association largely explained by higher levels of identity concealment in higher-structural-stigma countries. Yet identity concealment was also associated with lower day-to-day discrimination and therefore protected against even lower life satisfaction. Conclusion The results emphasize the importance of changing discriminatory legislation and negative population attitudes to improve transgender people's life satisfaction, and also highlight targets for intervention at interpersonal and individual levels.
\end{abstract}

Keywords Transgender $\cdot$ Concealment $\cdot$ Minority stress $\cdot$ Life-satisfaction $\cdot$ Structural stigma $\cdot$ LGBT

\section{Introduction}

Studies increasingly show that transgender people, namely those who experience incongruity between their sex assigned at birth and current gender identity, are at particular risk of mental health concerns, psychological distress, and other indicators of poor life satisfaction [1, 2]. In particular, studies have reported a higher incidence of psychiatric problems, such as anxiety and depression [3, 4], and a higher degree of suicidal ideation and suicide attempts among transgender people compared to the general population $[3,5]$.

Richard Bränström

richard.branstrom@ki.se

1 Division of Psychology, Department of Clinical Neuroscience, Karolinska Institutet, Nobels väg 9, 17177 Stockholm, Sweden

2 Department of Social and Behavioral Sciences, Yale School of Public Health, New Haven, CT, USA
Transgender people's higher risk of poor mental health is believed to be a consequence of their increased exposure to stigma and minority stress compared to individuals without transgender experience, that is, cis-gender individuals [6, 7]. Stigma occurs and can influence the mental health and wellbeing of transgender people at multiple levels. At the structural level, stigma is expressed as unjust laws, policies, and cultural norms that deny, or fail to protect, the equal rights of minority populations $[5,8,9]$. At the interpersonal level, stigma manifests as discrimination in social interactions, victimization, non-affirmation of gender identity, and other expressions of prejudice in interactions between individuals $[7,10,11]$. At the individual level, stigma can reduce transgender people's coping resources by requiring maladaptive behavioral strategies, such as concealment of transgender identity and social isolation [12], as well as internalized forms of transphobia and negative expectations for future events [7]. The extent to which transgender people are exposed to these types of interpersonal and individuallevel experiences is believed to be a consequence of stigma at a structural level and the degree of transgender hostility in 
the environment surrounding a transgender individual $[8,9]$. Each of these forms of stigma is believed to put transgender people at increased risk of poor mental health [6].

Structural stigma is usually measured as discriminatory laws and policies and prejudicial attitudes towards the stigmatized [9]. Examining the relationship between structural stigma and the health of the stigmatized requires large datasets with sufficient numbers of stigmatized respondents distributed across geographical units, such as countries, that are diverse in terms of structural stigma. Because most previous studies of transgender health and life experiences have been conducted in small samples within a single country or municipality, larger-scale examinations of the association between structural stigma on transgender people's wellbeing have not previously been possible $[1,6]$. One exception is a study conducted in the US that found that structural stigma at the state level was associated with lower odds of lifetime suicide attempts among transgender adults [5]. Yet, in this study, structural stigma toward sexual minority individuals (e.g., those who identify as gay and lesbian) was used as a proxy for transgender-specific structural stigma due to the insufficient variation in transgender-specific structural stigma across US states at the time of study. Research has since identified the importance of using structural stigma indicators specific to the population of study [13]. Because transgender people have distinct health determinants from sexual minority individuals [6], such as legal facilitators of and barriers to gender affirmation [2], examining the association between transgender-specific structural stigma and health-related outcomes represents an important research aim not previously addressed. Because structural stigma surrounding transgender people is currently highly variable across European countries, European-wide studies of transgender people represent a suitable opportunity for examining associations between transgender-specific structural stigma and indicators of this population's health and wellbeing.

The purpose of this study was to investigate the association between transgender-specific structural stigma, measured as country-level laws, policies, and community attitudes toward transgender people, and transgender people's life satisfaction. We further explored the role of interpersonal- and individual-level forms of stigma in explaining this association. We specifically hypothesized that the association between structural stigma and life satisfaction would be mediated by exposure to discrimination, an interpersonal form of stigma consistently associated with poor health-related outcomes [14]. According to this hypothesis, we expected that transgender people would be exposed to more day-to-day discrimination in countries with greater structural stigma, which compromises their life satisfaction (see Fig. 1a). We also hypothesized that
Fig. 1 a, b Conceptual model of associations among structural, interpersonal, and individual levels of stigma predicting lifesatisfaction among transgender people
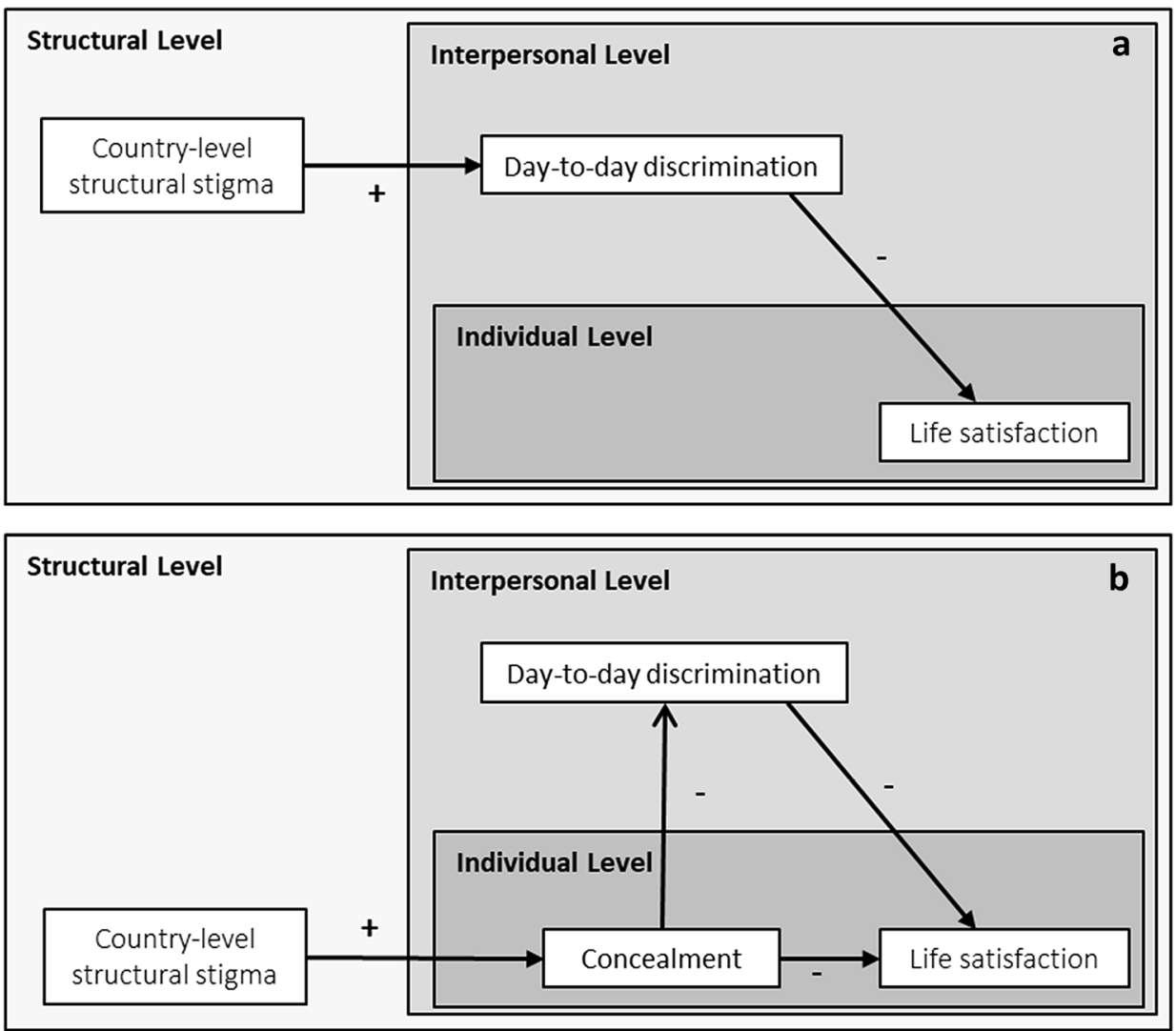
the association between structural stigma and life satisfaction would be mediated through transgender identity concealment. Following this hypothesis, we expected that transgender people would be more likely to conceal their gender identity in countries with greater structural stigma, thereby explaining their lower life satisfaction in those countries. At the same time, because concealment can protect against discrimination [15], we also hypothesized a serial mediation whereby structural stigma predicts greater concealment to predict lower discrimination to predict life satisfaction. In this case, the association between structural stigma and poor life satisfaction is expected to be smaller than it otherwise would be if discrimination and its association with lower concealment were not taken into account (see Fig. 1b).

To explore these hypotheses, we took advantage of the European Union Lesbian, Gay, Bisexual, and Transgender (EU-LGBT) survey, containing one of the largest-known international samples of transgender people. In addition to covering a geographic area diverse in structural stigma surrounding transgender people, the EU-LGBT survey contains a validated measure of life satisfaction that has demonstrated a strong link with other important indicators of health and wellbeing $[16,17]$, in addition to measures of interpersonal (i.e., discrimination) and individual (e.g., identity concealment) variables that hypothetically operate as mechanisms between structural stigma and life satisfaction. To our knowledge, this is the first international investigation of structural stigma and transgender people's wellbeing. It is also the first study to examine potential individual and interpersonal mechanisms that could explain this association.

\section{Methods}

\section{Study sample}

This study uses data from the European Union Lesbian, Gay, Bisexual, and Transgender (EU-LGBT) survey [18], which surveyed the treatment of and wellbeing of lesbian, gay, bisexual, and transgender (LGBT) individuals in 28 European countries using a web-based survey between April and July 2012. The sample included individuals 18 years of age or older who identified as LGBT and lived in one of the 28-member states of the European Union. Participants were recruited via internet advertisements posted on over 400 local, national, and international LGBT websites and via national LGBT organizations. The survey was completed by a total of 93,079 participants, 6771 (7.3\%) of whom selfidentified as transgender. The survey development and methods have been described in detail elsewhere [18].

\section{Self-report measures}

\section{Transgender identity}

Individuals were classified based on their responses to an item assessing current or life-time experiences as a transgender individual, with the question: "Are you/have you been a transgender person?" with response options: "yes," or "no." A total of 6771 individuals self-identified as transgender in the survey.

\section{Life-satisfaction}

Participants' general life satisfaction was assessed with the question: "All things considered, how satisfied would you say you are with your life these days?" Respondents indicated their response on a scale from 1 (very dissatisfied) to 10 (very satisfied). This question was the same as a question used in the World Values Survey [19], in which it has been asked every year from 1981 to 2009 and shown high consistency ( $r=0.78$ ) across time and countries [17]; it has also shown high stability within individuals [20] and has consistently been shown to be linked to numerous indicators of health and wellbeing $[16,17]$.

\section{Concealment of transgender identity}

Concealment of transgender identity was assessed as degree of openness about transgender identity to the following groups of people: "family members," "friends," "neighbors," and "work colleagues/schoolmates," with the question: "To how many people among the following groups are you open about yourself being transgender?" Response options included the following: "none [coded =0]," "a few [coded =1]," "most [coded=2]," "all [coded=3]." We calculated an average score based on the openness indicated across the four groups above. Concealment was dichotomized at an average score across the four groups of 1.0 (i.e., "a few"), so that participants with an average score of less than 1.0 were categorized as 'concealed' and those scoring 1.0 or higher as 'not concealed.'

\section{Everyday discrimination}

An adapted eight-item scale was used to assess respondents' exposure to everyday discrimination [21]. In response to the question: "In the last 6 months, in your day-to-day life, how often have any of the following things happened to you because you are or are assumed to be transgender?," respondents were asked to indicate exposure to events, such as "You have been treated with less courtesy than other people," and "You have been treated with less respect than other people." Response options included the following: "never 
happened in the last sixth months [coded $=0$ ]," "happened only once in the last 6 months [coded $=1]$," "2-5 times in the last 6 months [coded $=3.5$ ]," and " 6 times or more in the last 6 months [coded =6]." Responses to the eight items were summed as an indicator of perceived discrimination during the past 6 months.

\section{Covariates}

Age, gender, relationship status, ethnic minority status, education, annual household income, type of living area (i.e., 'urban' or 'rural'), and country of birth were included as individual-level socio-demographic factors.

\section{County-level characteristics}

\section{Country-level structural stigma}

We created a measure of structural stigma related to transgender identity in 2012 for all EU countries following similar prior research on structural stigma toward other stigmatized populations [22]. We first created an index of laws and policies concerning transgender people collected by the International Lesbian, Gay, Bisexual, Trans and Intersex Association in Europe [23]. The index of laws and policies was created by summing across four domains of discrimination and protections (i.e., asylum provisions based on gender identity, constitutional and legal protections against discrimination toward transpeople, marriage recognition for transgender people, legal gender recognition). Each form of discrimination was assigned a negative point, whereas each form of protection was assigned a positive point. These points were then summed to create a scale from -7 to 13 . We then combined this index with a measure of social attitudes from the European Commission's survey: "Special Eurobarometer 393-Discrimination in the EU in 2012," a European population-based survey of 26,622 participants' responses regarding attitudes towards social issues [24]. To assess attitudes towards transgender people, participants were asked to rate to what degree they would feel comfortable with a transgender person in the highest political position in their country: "Using a scale from 1 to 10, please tell me how you would feel about having a transgender person in the highest elected political position in [COUNTRY]? Where ' 1 ' means that you would feel "totally uncomfortable" and " 10 " that you would feel "totally comfortable"." The index of laws and policies and the measure of population attitudes were both standardized by $z$-transformation and then averaged to create one score of structural stigma for each country. The correlation between the two measures was 0.31 . The final structural stigma score varied between the lowest score in the United Kingdom - 2.12 and the highest score in Latvia 1.56, with a higher value indicating a higher degree of structural stigma.

\section{Gini coefficient}

To adjust for each country's income equality—a known correlate of life satisfaction and positive attitudes towards sexual minorities-the Gini coefficient in 2012 for each country was included as a country-level covariate [25]. The Gini coefficient varies between 0 and 1 , whereby a low value indicates equality and a high value indicates major inequalities.

\section{County-level life-satisfaction}

Because the association between country-level structural stigma toward transgender persons and life satisfaction could potentially be explained by general country-level differences in life satisfaction, we controlled for average country-level self-reported life satisfaction as assessed in the general population of each country using the population-based European Social Survey [26].

\section{Statistical analysis}

To analyze data at both individual and country levels, multilevel models were used. Individual-level factors (i.e., life satisfaction, concealment, discrimination, and socio-demographic factors) were modeled at level 1 and country-level factors (i.e., structural stigma, Gini coefficient, and population-average life-satisfaction) were modeled at level 2. Fixed effects were estimated using maximum likelihood parameter estimation. The amount of missing data varied from $0 \%$ for sociodemographic variables (e.g., gender assigned at birth, age, country of residence) to $0.9 \%$ for life satisfaction. Only respondents with complete records on all study variables were included in analyses. The analyses were conducted using MPlus statistical software and the level for statistical significance in regression models was set at $\alpha=0.05$.

First, three separate models were calculated to estimate the association between country-level structural stigma and the primary outcome (i.e., life satisfaction) and the two proposed mediating variables (i.e., concealment of transgender identity and day-to-day discrimination). Second, since the association between structural stigma and concealment was significant, a multi-level mediation analysis was performed to estimate the indirect effect of country-level structural stigma and life satisfaction through concealment. Since the association between structural stigma and discrimination was non-significant, we did not examine an indirect effect of country-level stigma on life-satisfaction via discrimination. Third, to determine if concealment might protect sexual minorities from day-to-day discrimination and thereby protect them from even lower life satisfaction, we conducted an 
additional multi-level mediation analysis calculating both the indirect effect of structural stigma on life-satisfaction as mediated through concealment, and through the structural stigma $\rightarrow$ concealment $\rightarrow$ discrimination $\rightarrow$ life-satisfaction mediation path. Finally, to isolate the associations in our models to structural stigma operationalized as laws and policies only (and not also population attitudes), we re-ran this final analysis using an index of structural stigma composed of only country-level laws and policies. This permitted us to examine the stability of our associations across two different operationalizations of structural stigma.

\section{Results}

\section{Descriptive statistics}

The socio-demographic characteristics of the 6771 transgender people recruited to the EU-LGBT survey are presented in Table 1. The largest number of transgender participants lived in Germany $(n=1329)$ and the lowest number in Malta $(n=18)$. The large majority of respondents lived in an urban area and almost half (45.9\%) were younger than 30 years old.

\section{Association between country-level structural stigma and life satisfaction, concealment of transgender identity, and day-to-day discrimination}

Multilevel regression models adjusted for age, ethnic minority status, education level, income, relationship status, and urbanicity (level 1) and for country-level Gini coefficient and life-satisfaction (level 2) showed significant associations between structural stigma and life satisfaction (adjusted $\beta=-0.188 ; 95 \%$ confidence interval $[\mathrm{CI}]-0.364,-0.013$; $p=0.036$; Fig. 2a), as well as between structural stigma and concealment of transgender identity (adj. $\beta=0.347 ; 95 \%$ CI $0.223,0.471 ; p<0.001$; Fig. 2b). We found no significant association between structural stigma and day-to-day discrimination (adj. $\beta=-0.197 ; 95 \% \mathrm{CI}-0.482,0.088$; $p=0.176$ ).

\section{Concealment as mediator of the association between country-level structural stigma and life satisfaction}

The first multilevel mediation analysis examined the extent to which the relationship between structural stigma (level 2) and life satisfaction (level 1) could be explained by concealment of transgender identity (level 1). The model was adjusted for age, ethnic minority status, education level, income, relationship status, and urbanicity (level 1) and for country-level Gini coefficient and life-satisfaction
Table 1 Sociodemographic characteristics of individuals self-identifying as transgender in the European Union LGBT Survey 2012 $(n=6707)$

\begin{tabular}{|c|c|}
\hline & $n(\%)$ \\
\hline \multicolumn{2}{|l|}{ Sex assigned at birth } \\
\hline Female & $2556(38.1 \%)$ \\
\hline Male & $4151(61.9 \%)$ \\
\hline \multicolumn{2}{|l|}{ Age } \\
\hline $18-29$ years & $3073(45.8 \%)$ \\
\hline 30-39 years & $1536(22.9 \%)$ \\
\hline $40-49$ years & $1164(17.4 \%)$ \\
\hline $50-59$ years & $671(10.0 \%)$ \\
\hline 60 years or older & $263(3.9 \%)$ \\
\hline Ethnic minority status & $466(6.9 \%)$ \\
\hline \multicolumn{2}{|l|}{ Level of education } \\
\hline Less than university & $3610(53.8 \%)$ \\
\hline University education & $3097(46.2 \%)$ \\
\hline \multicolumn{2}{|l|}{ Household income } \\
\hline Under the lowest quartile & $2557(38.1 \%)$ \\
\hline Between the lowest quartile and median & $1696(25.3 \%)$ \\
\hline Between the median and highest quartile & $1320(19.7 \%)$ \\
\hline Above the highest quartile & $1134(16.9 \%)$ \\
\hline \multicolumn{2}{|l|}{ Urbanicity } \\
\hline Living in an urban area & $5792(86.4 \%)$ \\
\hline Living in a rural area & $915(13.6 \%)$ \\
\hline \multicolumn{2}{|l|}{ Relationship status } \\
\hline Single & $3206(47.8 \%)$ \\
\hline In a relationship, not living with a partner & $1558(23.2 \%)$ \\
\hline Live with a partner & $1943(29.0 \%)$ \\
\hline \multicolumn{2}{|l|}{ Sexual orientation } \\
\hline Lesbian & $1236(18.4 \%)$ \\
\hline Gay & $1720(25.6 \%)$ \\
\hline Bisexual & $1818(27.1 \%)$ \\
\hline Heterosexual & $898(13.4 \%)$ \\
\hline Other & $746(11.1 \%)$ \\
\hline Don't know & $289(4.3 \%)$ \\
\hline
\end{tabular}

at (level 2). The indirect effect of the association between structural stigma and life-satisfaction through concealment of transgender identity was significant (adj. $\beta=-0.336$; 95\% CI $-0.473,-0.199 ; p<0.001)$. When controlling for concealment of transgender identity, the relationship between structural stigma and life-satisfaction was no longer significant.

\section{Concealment of transgender identity as protection against day-to-day discrimination}

In a second multilevel mediation model, we investigated whether structural stigma predicts greater concealment to predict lower discrimination to predict life satisfaction. 
Fig. 2 a, b Mean country-level self-reported life-satisfaction (a) and mean proportion of transgender people reporting high level of concealment of their transgender identity (b) among transgender people across Europe by country-level structural stigma a

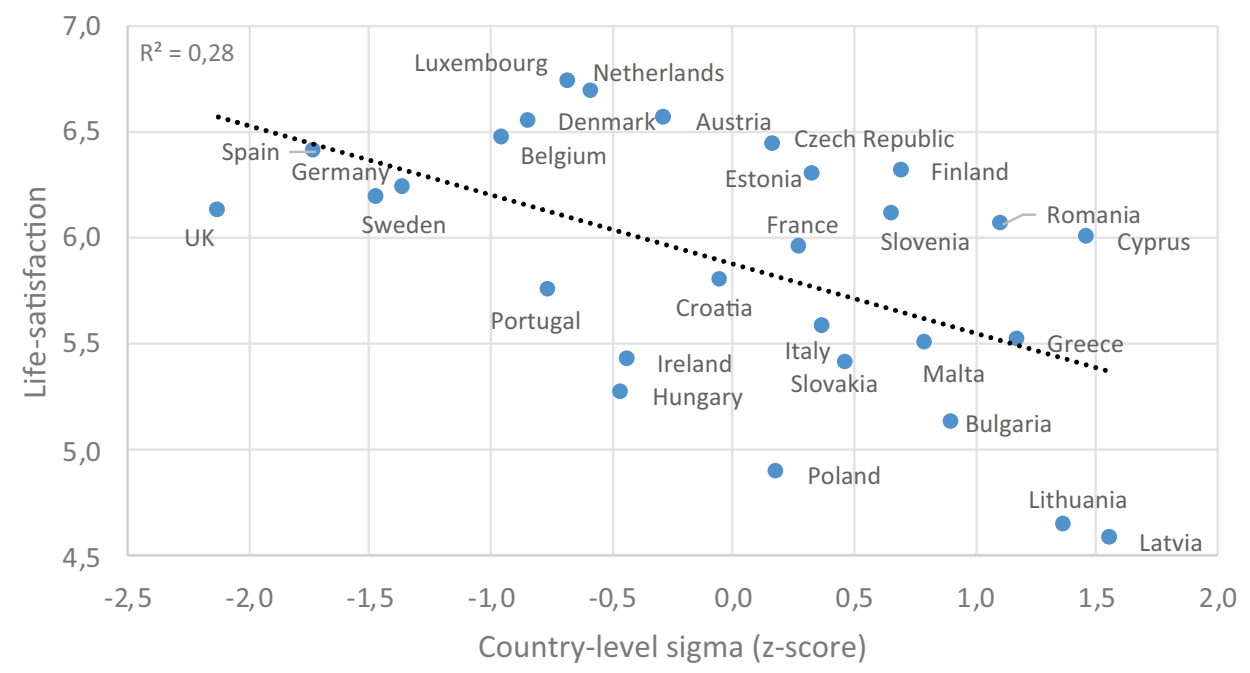

b

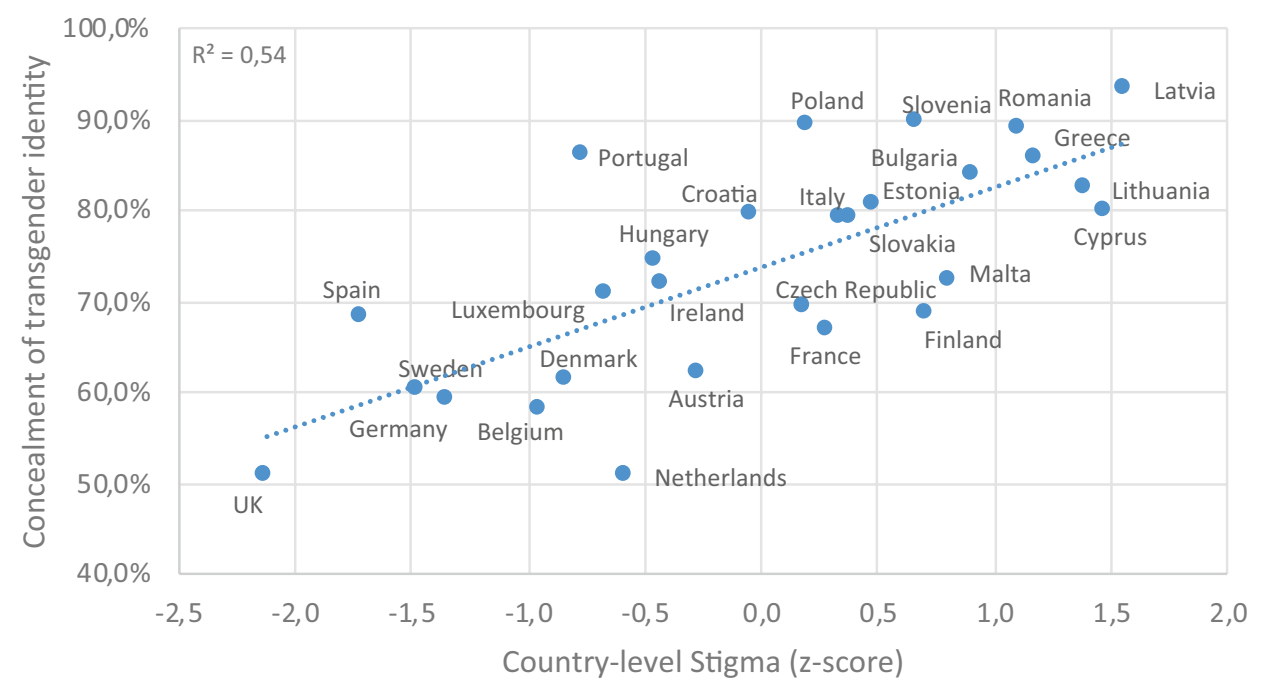

The results presented in Fig. 3 show that concealment significantly mediated the association between structural stigma and life satisfaction and that this association was still significant in the context of discrimination (adj. $\beta=-0.411 ; 95 \% \mathrm{CI}-0.575,-0.247 ; p<0.001)$. The indirect serial mediating effect of the association between country-level stigma and life-satisfaction (i.e., stigma $\rightarrow$ concealment $\rightarrow$ discrimination $\rightarrow$ life-satisfaction) was also significant (adj. $\beta=0.070 ; 95 \%$ CI 0.034 , $0.105 ; p<0.001)$. Therefore, the results indicate that concealment of transgender identity mediates the association between structural stigma and transgender people's life satisfaction both directly and indirectly by reducing exposure to day-to-day discrimination.

To test the stability of our findings regarding associations with stigma at the structural-level, we re-ran this analysis using only country-level laws and policies as an indicator of county-level structural stigma and found a similar pattern of results (see Supplementary Fig. S1).

\section{Discussion}

Although numerous non-probability studies indicate that transgender people experience more mental health problems, physical health concerns, and other indicators of poor life satisfaction than cis-gender individuals $[1,2,6]$, to our knowledge, this is the first study to demonstrate an association between structural stigma and transgender people's life satisfaction using an index of transgender-specific structural stigma. Using a unique dataset with responses from a large group of transgender people across Europe, this study documents potential mechanisms through which countrylevel structural stigma might exert its effect. In addition to 


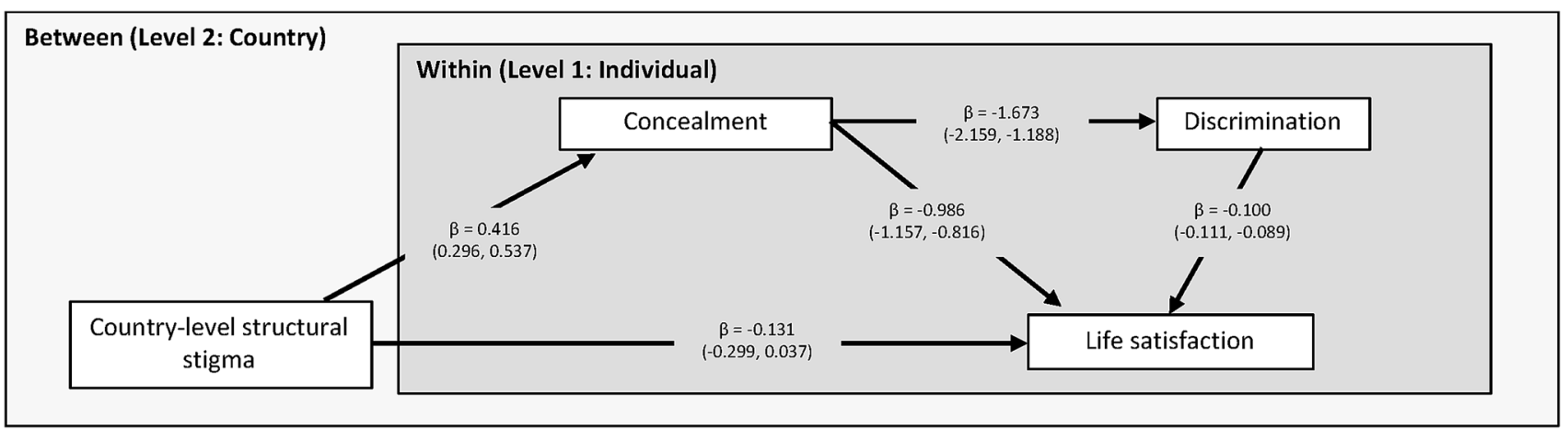

Indirect effect of Country-level stigma -> Concealment-> Life-Satisfaction: $-0.411(-0.575,-0.247)$

Indirect effect of Country-level stigma -> Concealment-> Discrimination-> Life-Satisfaction: 0.070 (0.034, 0.105)

Fig. 3 Multilevel mediation model of the association of country level structural stigma with life-satisfaction among transgender people across Europe mediated through transgender identity concealment and experiences of day-to-day discrimination

showing that transgender people living in a country with a higher degree of structural stigma, measured by discriminatory laws, policies, and population attitudes, report lower life satisfaction compared to transgender people living in countries with lower degrees of structural stigma, results also show that this association could largely be explained by transgender people's concealment of their identity. At the same time, findings indicate a potentially protective effect of identity concealment on transgender people's exposure to day-to-day discrimination that further explains the association between structural stigma and life satisfaction.

These results are consistent with existing research demonstrating the negative impact of stigma and minority stress on sexual minority populations $[9,27]$. Yet, this is the first know study to extend these findings to document the association between transgender-specific structural-level stigma and transgender people's well-being. A particular strength of the study was its ability to examine manifestations of stigma across multiple socioecological levels, including structural (country-level discriminatory legislation and population attitudes), interpersonal (day-to-day discrimination), and individual (identity concealment), and their associations with our outcome, thereby extending the field of stigma studies that has tended to examine these levels of stigma in isolation [9].

Contrary to expectations and prior results among sexual minorities across Europe [27], we did not find a significant differences between high-stigma and low-stigma countries in terms of the degree to which transgender people were exposed to discrimination. One possible reason for this may be the concealability of one's transgender status. Transgender people whose transgender identity is visible to others are exposed to more negative treatment than those whose identities are more concealable [6]. Supporting this, the results of this study show that transgender people who were open with their identity were subjected to more discrimination than transgender people who concealed their identity and that concealment was more common in countries with high structural stigma toward transgender persons. These findings suggest that transgender people perhaps make the tradeoff between the protections and constraints of concealment at least partially informed by their social context, consistent with decision-making models of identity disclosure [28, 29]. At the same time, numerous studies have demonstrated the negative impact of identity concealment on well-being $[15,27]$. While transparency about one's identification can facilitate access to support and belongingness from similar others [30] and appropriate and affirmative healthcare [3], this study indicates that openness is associated with higher exposure to day-to-day discrimination and lower life satisfaction. Therefore, the safety of one's structural and interpersonal surroundings are paramount in considerations of identity disclosure or visibility and clinicians should take all necessary steps to ensure and support such safety.

This study emphasizes the importance of reducing stigma across structural, interpersonal, and individual levels. Specifically, findings suggest that implementing changes in legislation and population attitudes toward transgender people can perhaps yield a significant impact in life satisfaction. Of particular importance for transgender people are efforts to reduce stigma in healthcare settings since many transgender people rely on such services. Examples of changes in legislation and policies that could reduce stigma in healthcare settings are removal of gender identity disorder diagnoses, compulsory requirements of sterilization to access gender affirming care, and other barriers to change of legal gender. Even though efforts to reduce discriminatory legislation and policies have been made in several European countries during the past several years, day-to-day discrimination is commonly reported among transgender people in all European countries, regardless of structural stigma, suggesting that bias-reduction interventions might also be an 
important route to improving transgender people's wellbeing [31]. Finally, supporting personal resilience through mental health interventions could help transgender people cope with the stress of structural and interpersonal forms of stigma, in ways that support personal and community empowerment in the face of these systemic conditions [32].

Despite being derived from a large international dataset of transgender people and taking advantage of multi-level assessments of transgender stigma, these study results must be considered in light of several limitations. First, participants were self-selected into the study and it is unknown how representative participants might be of the total transgender population in their respective countries. Second, we had limited information about transgender-specific experiences and gender identities of participants, thereby making it impossible to examine other mechanisms or stratify analyses based on important within-group characteristics. Without having assessed stigma directed toward other marginalized social statuses across levels, such as ethnic/racial minority, immigrant, or socioeconomic, the present study could not permit examining intersections of this stigma with stigma directed to gender minority identity. Research using an intersectional framework represents an important future direction for examining potential moderators of the associations found here [33]. Third, this study relies on a single-item indicator of life satisfaction. The item used, however, has shown high consistency across large-scale studies in many different country contexts and across time [17, 20], and it has shown a strong link with a multitude of indicators of mental, physical, and social health [16, 17]. Nevertheless, only future research assessing broader aspects of health and wellbeing will be able to further increase our knowledge about in impact of stigmatizing environments on transgender people. Fourth, the questions used to assess day-to-day discrimination and concealment of transgender status have not been extensively validated. It is therefore unclear how accurately these non-validated measures might have captured these experiences of study participants. Future measures validation studies among transgender people is needed to strengthen our understanding of the impact of these factors on transgender people's life satisfaction. Fifth, the crosssectional nature of the study design makes it impossible to draw causal conclusions and only future studies with longitudinal designs can help clarify the causal pattern though which changes in stigmatizing environment might causally influence the lives of transgender people. Finally, since the study was conducted among European Union member states it is difficult to assess how well these findings represent the situation of transgender people outside of Europe. Several of the European countries included in our study are among the least stigmatizing towards transgender people both regarding legislation/policies and population attitudes, it is possible that the pattern of associations among stigma, discrimination, and identity concealment look somewhat different in countries with even higher levels of stigma than those represented within the European context. Populationrepresentative studies outside of Europe can test the generalizability of the present findings.

In sum, this study finds a negative association between structural stigma and life satisfaction among transgender people in Europe. The differences in transgender people's life satisfaction across countries can largely be explained by how open or concealed they are about their transgender identity. The results show the strong role that structural forms of stigmatization can play in transgender people's lives and wellbeing. The results emphasize the importance of changing discriminatory legislation and negative population attitudes to improve the situation of transgender people, and also highlight targets for intervention at the interpersonal and individual levels.

Supplementary Information The online version contains supplementary material available at https://doi.org/10.1007/s00127-021-02036-6.

Author contributions RB and JEP both participated in the conception and analytic strategies of the current study. RB had full access to all the data in the study and takes responsibility for the integrity of the data and the accuracy of the data analysis. Both authors made substantial contributions to the interpretation of the data, as well as drafting and revision of the text, and approved of the final version of the manuscript.

Funding Open Access funding provided by Karolinska Institute. This work was supported by the Swedish Research Council [2016-01707; 2018-01876] and the Swedish Research Council for Health, Working Life, and Welfare (Nr: 2014-0173; 2018-01628). The funding sources had no involvement in the study design, data collection, analyses, interpretation of data, or the reporting of findings.

Data availability Data is available under special license agreement at the UK Data Service (https://ukdataservice.ac.uk/).

Code availability Please, contact the corresponding author.

\section{Compliance with ethical standards}

Conflict of interest The authors have no conflict of interest to disclose.

Ethical approval The study has been approved by the Regional Ethics Committee in Stockholm (No. 2017/1852-31/5).

Open Access This article is licensed under a Creative Commons Attribution 4.0 International License, which permits use, sharing, adaptation, distribution and reproduction in any medium or format, as long as you give appropriate credit to the original author(s) and the source, provide a link to the Creative Commons licence, and indicate if changes were made. The images or other third party material in this article are included in the article's Creative Commons licence, unless indicated otherwise in a credit line to the material. If material is not included in the article's Creative Commons licence and your intended use is not permitted by statutory regulation or exceeds the permitted use, you will need to obtain permission directly from the copyright holder. To view a copy of this licence, visit http://creativecommons.org/licenses/by/4.0/. 


\section{References}

1. Dhejne C, Van Vlerken R, Heylens G, Arcelus J (2016) Mental health and gender dysphoria: a review of the literature. Int Rev Psychiatry 28(1):44-57

2. Reisner SL, Poteat T, Keatley J, Cabral M, Mothopeng T, Dunham E, Holland CE, Max R, Baral SD (2016) Global health burden and needs of transgender populations: a review. Lancet 388(10042):412-436

3. Bränström R, Pachankis JE (2020) Reduction in mental health treatment utilization among transgender individuals after genderaffirming surgeries: a total population study. Am J Psychiatry 177(8):727-734

4. Connolly MD, Zervos MJ, Barone CJ II, Johnson CC, Joseph CL (2016) The mental health of transgender youth: advances in understanding. J Adolesc Health 59(5):489-495

5. Perez-Brumer A, Hatzenbuehler ML, Oldenburg CE, Bockting W (2015) Individual-and structural-level risk factors for suicide attempts among transgender adults. Behav Med 41(3):164-171

6. White Hughto JM, Reisner SL, Pachankis JE (2015) Transgender stigma and health: a critical review of stigma determinants, mechanisms, and interventions. Soc Sci Med 147:222-231. https ://doi.org/10.1016/j.socscimed.2015.11.010

7. Testa RJ, Habarth J, Peta J, Balsam K, Bockting W (2015) Development of the gender minority stress and resilience measure. Psychol Sex Orientat Gend Divers 2(1):65

8. Hatzenbuehler ML, Pachankis JE (2016) Stigma and minority stress as social determinants of health among lesbian, gay, bisexual, and transgender youth: research evidence and clinical implications. Pediatr Clin N Am 63(6):985-997. https://doi.org/10.1016/j. pcl.2016.07.003

9. Hatzenbuehler ML (2016) Structural stigma: research evidence and implications for psychological science. Am Psychol 71(8):742-751. https://doi.org/10.1037/amp0000068

10. Blondeel K, de Vasconcelos S, García-Moreno C, Stephenson R, Temmerman M, Toskin I (2018) Violence motivated by perception of sexual orientation and gender identity: a systematic review. Bull World Health Organ 96(1):29-41

11. Hatzenbuehler ML, Phelan JC, Link BG (2013) Stigma as a fundamental cause of population health inequalities. Am J Public Health 103(5):813-821. https://doi.org/10.2105/ajph.2012.301069

12. Bockting WO, Miner MH, Swinburne Romine RE, Hamilton A, Coleman E (2013) Stigma, mental health, and resilience in an online sample of the US transgender population. Am J Public Health 103(5):943-951

13. Hatzenbuehler ML, Rutherford C, McKetta S, Prins SJ, Keyes KM (2020) Structural stigma and all-cause mortality among sexual minorities: differences by sexual behavior? Soc Sci Med 244:112463

14. Pascoe EA, Smart Richman L (2009) Perceived discrimination and health: a meta-analytic review. Psychol Bull 135(4):531

15. Pachankis JE, Mahon CP, Jackson SD, Fetzner BK, Bränström R (2020) Sexual orientation concealment and mental health: a meta-analytic review. Psychol Bull 146(10):831-871

16. Bray I, Gunnell D (2006) Suicide rates, life satisfaction and happiness as markers for population mental health. Soc Psychiatry Psychiatr Epidemiol 41(5):333-337

17. Diener E, Inglehart R, Tay L (2013) Theory and validity of life satisfaction scales. Soc Indic Res 112(3):497-527
18. European Union Agency for Fundamental Rights (2014) European Union lesbian, gay, bisexual and transgender survey - EU LGBT survey. Vienna, Austria

19. Inglehart R, Basáñez M, Díez-Medrano J, Halman L, Luijkx R (2004) World values surveys and European values surveys, 1999-2001. Inter-university Consortium for Political and Social Research, Ann Arbor, MI

20. Pavot W, Diener E (1993) The affective and cognitive context of self-reported measures of subjective well-being. Soc Indic Res 28(1): $1-20$

21. Williams DR, Yu Y, Jackson JS, Anderson NB (1997) Racial differences in physical and mental health: Socio-economic status, stress and discrimination. J Health Psychol 2(3):335-351

22. Pachankis JE, Hatzenbuehler ML, Berg RC, Fernandez-Davila P, Mirandola M, Marcus U, Weatherburn P, Schmidt AJ (2017) Anti-LGBT and anti-immigrant structural stigma: an intersectional analysis of sexual minority men's HIV risk when migrating to or within Europe. J Acquir Immune Defic Syndr. https://doi. org/10.1097/qai.0000000000001519

23. ILGA-Europe the European region of the international lesbian, gay, bisexual, trans and intersex (2015) Rainbow Europe map and index (2005-2015). Brussels, Belgium

24. European Commission (2015) Special Eurobarometer 437: "discrimination in the EU in 2015". Brussels. https://doi. org/10.2838/499763

25. Andersen R, Fetner T (2008) Economic inequality and intolerance: attitudes toward homosexuality in 35 democracies. Am J Polit Sci 52(4):942-958

26. Norwegian Social Science Data Services (2002-2017) ESS round 1-8: European social survey round 1-8 data

27. Pachankis JE, Bränström R (2018) Hidden from happiness: structural stigma, sexual orientation concealment, and life satisfaction across 28 countries. J Consult Clin Psychol 5(86):403-415

28. Hatzenbuehler ML, McLaughlin KA, Nolen-Hoeksema S (2008) Emotion regulation and internalizing symptoms in a longitudinal study of sexual minority and heterosexual adolescents. J Child Psychol Psychiatry 49(12):1270-1278. https://doi.org/10.111 $1 / \mathrm{j} .1469-7610.2008 .01924 . x$

29. Chaudoir SR, Fisher JD (2010) The disclosure processes model: understanding disclosure decision making and postdisclosure outcomes among people living with a concealable stigmatized identity. Psychol Bull 136(2):236-256. https://doi.org/10.1037/ a0018193

30. Hendricks ML, Testa RJ (2012) A conceptual framework for clinical work with transgender and gender nonconforming clients: an adaptation of the minority stress model. Prof Psychol Res Pract 43(5):460

31. Broockman D, Kalla J (2016) Durably reducing transphobia: a field experiment on door-to-door canvassing. Science 352(6282):220-224

32. Pachankis JE, Williams SL, Behari K, Job S, McConocha EM, Chaudoir SR (2020) Brief online interventions for LGBTQ young adult mental and behavioral health: a randomized controlled trial in a high-stigma, low-resource context. J Consult Clin Psychol 88(5):429

33. Wesp LM, Malcoe LH, Elliott A, Poteat T (2019) Intersectionality research for transgender health justice: a theory-driven conceptual framework for structural analysis of transgender health inequities. Transgender Health 4(1):287-296 